\title{
A ESPECTROMETRIA DE RAIOS GAMA NA PROSPECC̣ÃO DE SULFETOS EM ROCHAS ALTERADAS HIDROTERMALMENTE
}

\author{
PIETRO GAZZERA MINUCCI*
}

\begin{abstract}
Potassium is added in the hydrothermally altered rocks by the percolating solutions, in a sufficient quantity to be detected by surface or aerial spectrometry. The current models for alteration zoning explain the high potassium content. The Gamma-Ray Spectrometry is an useful geophysical method in the aerial exploration for disseminated or massive sulphide deposits of hydrothermal origin, as it was again proved in Camaqua area, South Brazil.
\end{abstract}
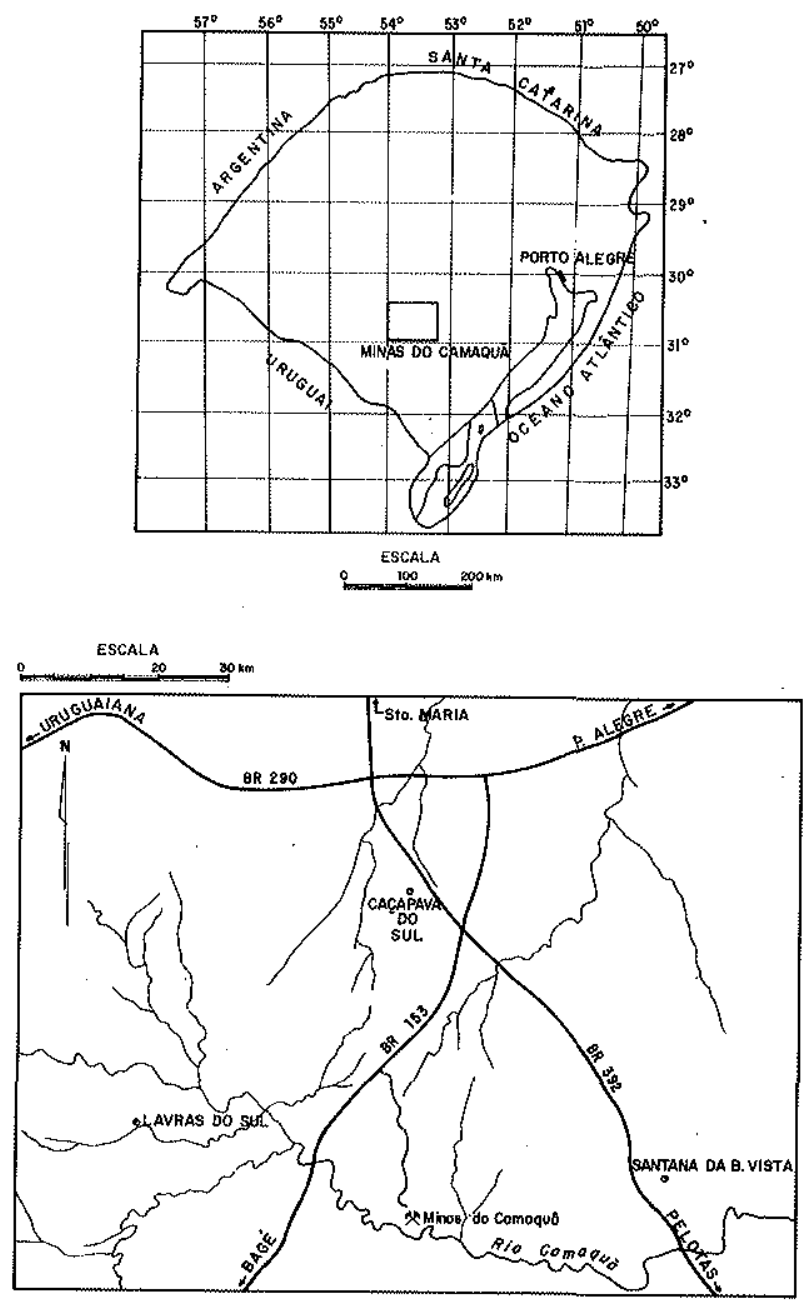

Figura 1 - Mapas de situação (Minas do Camaquā)

INTRODUÇÃo Em 1973, contratada pela CPRM, a Texas Instruments Inc. realizou levantamentos aerogeofísicos e geológicos em extensa área $\left(30.000 \mathrm{~km}^{2}\right)$ do escudo sul-rio-grandense (Jackson, 1973) et al.

Os métodos geofísicos aplicados foram a magnetometria e a espectrometria para a deteç̧ão indireta dos elementos urânio, tório e potássio. Praticamente nenhu- ma importancia relativa foi dada às anomalias de potássio desde sua apresentação em relatório pela Texas Inc., apesar dos intensos trabalhos de pesquisa mineral desenvolvidos na regiao por diversas companhias, fato devido à pouca divulgacăo e pouco conhecimento de seu significado, e ao tipo de mapas apresentados.

Os fatos que motivaram o estudo e a compilação resumidos neste artigo foram a recente descoberta de importante depósito mineral de chumbo e zinco a $5 \mathrm{~km}$ para SW das minas de cobre de Camaquã, pela geoquímica de sedimentos de corrente e solos, em lugar onde já haviam sido apontadas anomalias aeroespectrométricas de $+2 \mathrm{a}+3$ desvios-padrão acima do background para o elemento potássio, e a correlação constatada entre as ocorrências de sulfetos conhecidas e os altos para potássio na área prospectada por aerogeofísica.

DEPOSITOS HIDROTERMAIS Os depósitos epigenéticos de origem hidrotermal são formados pela interação dos fluidos mineralizadores associados a ambientes magmáticos ou metamórficos, com as rochas percoladas, as quais sofrem metassomatose de tipo e grau determinados pelo tipo de rocha presente e pelas condiçōes físico-químicas do fluido, estas variáveis à medida que percola através da rocha encaixante.

A formação de um depósito hidrotermal é um processo dinâmico, sendo que num certo instante determinados elementos são incorporados à rocha em um trecho do percurso do fluido enquanto outros são lixiviados e depositados mais adiante, podendo, em instante posterior, ser novamente mobilizados.

Pode-se imaginar esse processo de formação como um avanço (no espaço) dos vários tipos de alteraçào. A Fig. 2, extraída do livro de Smirnov (1976), esquematiza a idéia acima para um caso em que a rocha encaixante é vulcânica.

Os tipos de alteração hidrotermal são classificados segundo os minerais formados, os quais comumente ocorrem em conjuntos, formando associaçð̄es minerais típicas das condiçס̃es de formação. Por exemplo, estudos detalhados feitos por Rose (1970) e Lowell (1970) sobre os porphyry copper do oeste americano, permitiram identịficar formalmente zonas de alteração, concêntricas, conforme mostra a Fig. 3, adaptada de Rose. 


\begin{tabular}{|c|c|c|c|c|}
\hline \multirow{4}{*}{$\begin{array}{c}\text { Porosidado } \\
\text { to }\end{array}$} & ALTA & 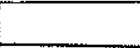 & \multirow{2}{*}{\multicolumn{2}{|c|}{ 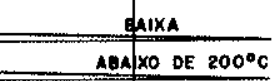 }} \\
\hline & SSIMAOE $400^{\circ} \mathrm{C}$ & & & \\
\hline & ENTAE 4.0 & & & ENTAE : 0.8 \\
\hline & & & & \\
\hline 8 & (ca) & & & \\
\hline E & (F) & 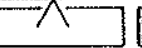 & W & 躍 \\
\hline 8 & $\left(M_{0}\right) \pi$ & & W & 7 \\
\hline 总 & (k) & $\sqrt{7 \sqrt{12}}$ & (4) & \\
\hline$\frac{b}{z}$ & (No) & 7 & $\rightarrow=$ & 个 \\
\hline $\begin{array}{l}\text { Minorais } \\
\text { Tipomór ficos }\end{array}$ & 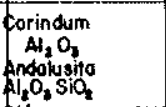 & $\begin{array}{r}\text { SERICI } \\
K \rho \cdot 3 \mathrm{AL}_{2} \mathrm{O}_{3} 6\end{array}$ & & $\begin{array}{l}\text { Epidoto } \\
\text { Fotisioj) } \\
\text { Colcifo } \\
\text { Coco, }\end{array}$ \\
\hline & $\begin{array}{l}\text { Piasporo } \\
\mathrm{A}_{2} \mathrm{O}, \mathrm{H}_{\mathrm{L}}\end{array}$ & & & \\
\hline Zoros metosomatienso & Quortzitico & $\begin{array}{l}\text { Quartzo } \\
\text { sericitico }\end{array}$ & $\begin{array}{l}\text { Sericitico } \\
\text { cloritica }\end{array}$ & $\begin{array}{c}\text { Clorítico } \\
\text { (propilífica) }\end{array}$ \\
\hline
\end{tabular}

Fígura 2 - Redistribuição de elementos por metassomatismo em rochas de origem vulcânica alteradas hidrotermalmente, com a energia do processo $\left(t^{\circ} \mathrm{C}\right)$ e a acidez $(\mathrm{pH})$ do meio dimjnuindo na frente do metassomatismo (branco $=$ perda; escuro $=$ ganho)

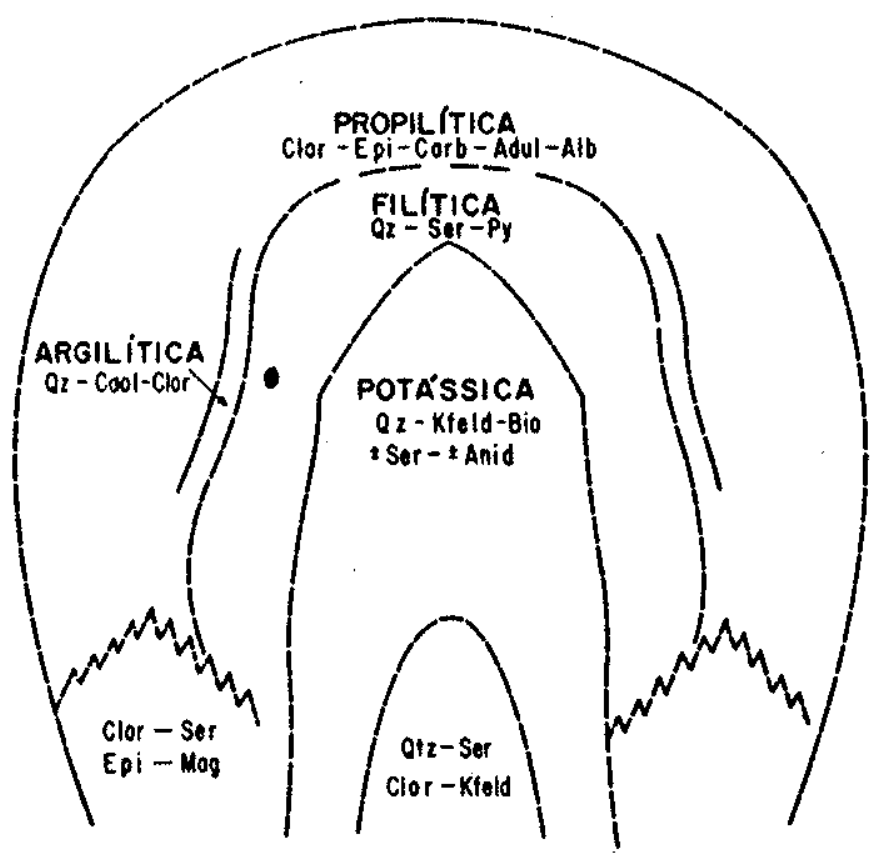

Figura 3 - Corte esquemático das zonas de alteraçðes na jazida de San Manuel, Arizona, EUA: Adul = adulária; Alb = albita; Anid = anidrita; Bio = biotita; Cao = caulim; Carb = carbonato; Clor = clorita; Epi $=$ epidoto; $\mathrm{Kfeld}=$ feldspato potássico; $\mathrm{Mag}=$ magnetita; $\mathrm{Py}=$ pirita; $\mathrm{Qz}=$ quartzo; $\mathrm{Qtz}=$ quartzito; $\mathrm{Ser}=$ sericita
ALGUNS ASPECTOS QUIMICOS Os modelos de zonação da alteração hidrotermal das rochas encaixantes, construídos com base nas observaçðes de campo sobre vários depósitos minerais, mostram um acréscimo relativo de minerais potássicos nos locais onde os fluidos mineralizadores percolaram (Moxham, 1965; Rose, 1970; Lowell, 1970; Davis, 1973) enquanto o elemento sódio tem seu teor diminuído. Isso leva à conclusão de que os fluidos são originalmente ricos em potássio, perdendo-o à medida que formam, por substituição, Kfeldspato (ortoclásio, microclínio, micropertita), biotita e sericita. Paralelamente, $o$ ataque do plagioclásio faz entrar em soluçăo o sódio e o cálcio, os quais, mais adiante no percurso do fluido, originarăo a albitização e a carbonataçăo (calcita em veios e grânulos no plagioclásio).

As reaçð̃es químicas são do tipo:

$$
\underset{\text { (anortita) }}{\mathrm{CaAl}_{2} \mathrm{Si}_{2} \mathrm{O}_{0}}+\underset{\mathrm{K}}{\mathrm{K}} \mathrm{O}+5 \mathrm{SiO}_{2}=\underset{\text { (K-feldspato) }}{2 \mathrm{KANSi}_{3} \mathrm{O}_{3}}+\mathrm{CaSiO}_{3}
$$

$$
\underset{\text { (albita) }}{2 \mathrm{NaAlSi}_{3} \mathrm{O}_{3}}+\mathrm{K}_{2} \mathrm{O}+\mathrm{SiO}_{2}=\underset{\text { (K-feldspato) }}{2 \mathrm{KAlSi}_{3} \mathrm{O}_{8}}+\mathrm{Na}_{2} \mathrm{SiO}_{3}
$$

CARACTERISTICAS GEOMETRICAS DA ZONAÇÃO A extensão em área do fenômeno da alteração provavelmente seja funçăo direta da permeabilidade da rocha, seja intrínseca ou induzida pela lixiviação de constituintes e tectonismo ruptural, e do valor do gradiente das pressóes. $O$ formato geométrico da zona de alteração hidrotermal é geralmente irregular e nåo obrigatoriamente simétrico relativamente ao depósito de sulfetos. Sua localização é determinada pelas estruturas geológicas que foram os condutos dos fluidos mineralizadores. Podem também existir rochas alteradas hidrotermalmente sem haver mineralizaçăo.

DETECÇÃo DAS ZONAS DE ALTERAÇÃo A detecção e caracterização das zonas de alteração é segura pela petrografia de seçào delgada. Na rocha in situ, a presenca e cristas ou relevo topográfico positivo pode ser indício de silicificaçăo. Macroscopicamente, cores e texturas incomuns à rocha são vistas se a alteraçăo for intensa.

As imagens de satélite, convenientemente processadas, também auxiliam na indicaçăo de áreas onde as rochas têm propriedades óticas ou térmicas distintas.

Outro método, pouco conhecido no meio geológico e geofísico brasileiro, é a espectrometria de raios gama para o elemento potássio, estudado em 1963 por Moxham, Foote e Bunker (1965), e em 1970 por Davis e Guilbert (1973), sobre os porphyries do Arizona, EUA.

Os autores desses estudos concluíram que a prospecçấo de jazidas hidrotermais pela radiometria é viável porque o potássio tem seu teor aproximadamente dobrado nas zonas onde há mineralizaçăo e seu comportamento concorda com os modelos correntemente aceitos de alteração hidrotermal.

TECNICA DA ESPECTROMETRIA DE RAIOS GAMA Modernamente, utiliza-se o cintilometro, cujo sensor é um cristal geralmente de NaI (ativado com tálio), para medir o fluxo natural da radiaçăo gama (fó- 
tons de alta energia), devido principalmente ao $\mathrm{Bi}^{214} \mathrm{da}$ série de desintegração do $\mathrm{U}^{238}$, ao $\mathrm{Tl}^{208}$ da série do $\mathrm{Th}^{232}$, e ao $\mathrm{K}^{40}$, existente sempre na proporção de $0,012 \%$ no potássio natural $\mathrm{K}^{39}$.

O espectrômetro é um cintilômetro e mede a energia de cada fóton capturado, energia esta característica do isótopo emissor. Assim, sâo construídos desde com três canais de energia até $\mathbf{4 0 0}$. $O$ instrumento mais simples é denominado apenas cintilometro e mede a radiaçao total (um canal). Os espectrômetros podem ser portáteis, montados em caminhơes e em aeronaves.

A técnica para a correção dos dados brutos obtidos de levantamentos feitos de aeronaves está hoje bem desenvolvida, havendo a utilização sistemática do computador para a depuração dos efeitos da mudança da distância ao terreno, radiação atmosférica, cósmica, e background da aeronave.

RESULTADOS OBTIDOS NO RS O levantamento aerogeofísico de 1973 foi realizado com um aviåo bimotor tipo Douglas DC-3, equipado com os instrumentos de aeroespectrometria de alta sensibilidade da Texas Instruments e um magnetômetro Geometrics G-803.

Os dados foram obtidos ao longo de linhas de vôo paralelas e orientadas segundo a direção $N 45^{\circ} \mathrm{W}$, com espaçamento de $1.000 \mathrm{~m}$, sendo que a altura de vôo foi de $125 \mathrm{~m}$. A velocidade média de operação do avião foi de $193 \mathrm{~km} / \mathrm{h}$.

O sistema instrumental utilizado pela Texas Instruments no levantamento de raios gama consistiu em seis detectores de cristal com 11 e $1 / 5$ pol de diâmetro por 4 pol de espessura, os quais emitem impulsos luminosos com a captura dos fótons de raios gama. Esses impulsos de luz são detectados por tubos fotomultiplicadores (sete por cristal), amplificados e transmitidos a um analisador multicanal, o qual assinala a amplitude do impulso a um dos $\mathbf{4 0 0}$ níveis de energia. Ao finalizar o periodo de contagem ( 2 segundos), os dados armazenados na memória do analisador junto a outros dados, como número de linha, altitude por radar, leituras magnetométricas, hora do dia, etc. são digitalizados e registrados em uma fita magnética.

Dois cristais adicionais e um tubo fotomultiplicador associado foram incorporados e conectados a um segundo analisador multicanal e a uma unidade de armazenamento de dados. Esses cristais estão protegidos dos raios gama incidentes no bojo da aeronave por uma chapa de chumbo de 2 pol de espessura e são usados para medir a radiatividade produzida pelo gás radônio 222 na atmosfera. O período de contagem é de 90 segundos.

Os dados digitalizados assim obtidos foram tratados por programas de computador e depurados dos efeitos alheios ds mediçoes requeridas. Com eles, a Texas Inc. construiu perfis rebatidos e os mapas que fazem parte do relatório final (Jackson, 1973).

Os mapas espectrométricos foram apresentados na escala 1:200.000, com curvas de contorno em funçåo do grau do desvio do background. No presente estudo, foram utilizados os perfis rebatidos com escala horizontal de 1:50.000, os quais possuem relativamente mais informaçס̃es.

Desse levantamento aerogeofísico resultaram diversas anomalias cintilométricas para urânio, tório e po- tássio, e magnéticas. Anomalias para o elemento potássio foram apontadas em Minas do Camaquã e na área vizinha de Santa Maria, entre outras localidades (Fig. 4).
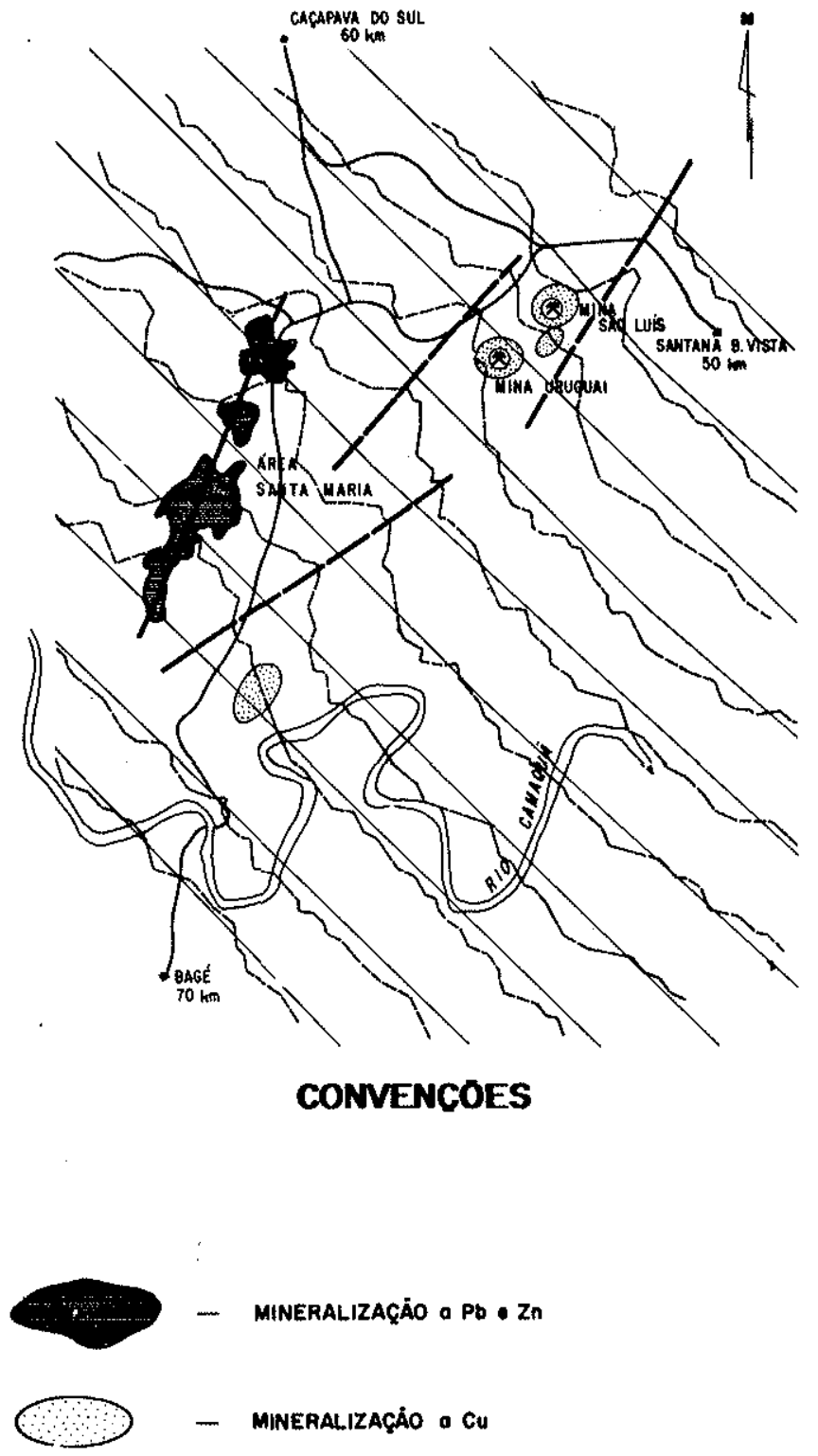

(

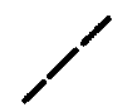

- alinhamento das anomalias espectrométricas

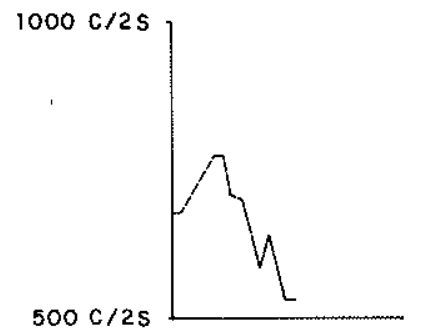

Figura 4 - Mapa de perfis rebatidos da espectrometria para $\mathrm{K}^{40}$ 
Minas do Camaquã é um distrito cuprífero minerado intermitentemente há um século, tendo sido por muito tempo a única lavra desse metal no Brasil. O distrito é composto por duas minas, Uruguai e São Luís, cujas reservas somam 30 milhoes de toneladas a $1 \%$ de cobre e várias ocorrências esparsas num raio de $2.000 \mathrm{~m}$. O minério é constitúdo por calcopirita, bornita, calcosina e pirita, em ganga de quartzo, calcita, clorita, hematita e barita. Apresenta-se sob forma filoneana, preenchendo fraturas de direçáo NW e como disseminaçðes laterais a elas. As rochas encaixantes são arenitos e conglomerados da Formaçăo Arroio dos Nobres, Grupo Bom Jar$\operatorname{dim}$ (eopaleozóico), as quais sofreram silicificação, caulinizaçăo, cloritização e sericitização, tipos de alteração que acompanham, com mais frequência, a mineralização primária (Bettencourt, 1972). A Fig. 5 mostra os resultados de análises químicas de amostras coletadas em uma galeria que intercepta um filão a calcopirita e bornita da mina São Luís. Observa-se o aumento relativo do $\mathrm{Fe}^{+2}$ sobre o $\mathrm{Fe}^{+3}$ no sentido do filaro, indicando condiçøes redutoras devidas ao enxofre causador da piritizaçâo. Os teores de potássio aumentam e os de sódio e cálcio diminuem pelas razóes mencionadas no item "Alguns aspectos químicos".

A área Santa Maria, cerca de $5 \mathrm{~km}$ para SW das minas de cobre, apresenta quatro corpos de minério alinhados segundo NE-SW. A rocha encaixante é um arenito provavelmente um pouco mais jovem (Formação Santa Barbara, do Grupo Camaquã?) que os aflorantes nas minas de cobre. Os principais minerais são esfalerita, galena e pirita, ocorrendo também, em algumas zonas, sulfetos de cobre. $O$ minério ocorre preenchendo fraturas de até alguns decimetros e como disseminaçð̋es na rocha. A petrografia de várias amostras relata crescimento autigenico dos grăos de quartzo e do microclínio, corrosão por carbonatos com mais ou menos ferro (calcita, siderita, ankerita) e a existência de cimento argiloso cujo aspecto feltroso sugere ter sido recristalizado
(Villwock, 1979). Análises por difração de raios X mostraram ser illita o argilomineral formado. Deste modo, segundo Villwock, o crescimento posterior de microclinio e a formação de illita explicam perfeitamente o enriquecimento em potássio que tais rochas apresentam, responsável pelas anomalias aeroespectrométricas. $\mathrm{Na}$ área Santa Maria, análises químicas para potássio de vinte amostras de arenito, coletadas em superfície numa zona onde há um pico de radiação gama para potássio, revelaram um teor médio de $\mathrm{K}$ igual a $5,9 \%$, com um desvio-padrão de 0,64 .

Além da localização de áreas alteradas hidrotermalmente, a utilidade do método de espectrometria de raios gama torna-se maior porque se pode muito facilmente, pela superposição do mapa de perfis rebatidos sobre o mapa geológico, identificar o controle geologico-estrutural da mineralização, uma vez que a distribuição do potássio guarda direta relaçăo espacial com o conduto dos fluidos mineralizadores.

Assim, para Minas do Camaquă, chega-se à conclusấo de que, embora as duas minas distem uma da outra $1,5 \mathrm{~km}$ sobre a linha nordeste e seus filoes principais tenham direção noroeste, o primeiro fato tem relação com a ascensão das soluçø̋́es através de zona de fraqueza nordeste (suposiçâo já feita por Bettencourt) não aparente em fotografias aéreas, mas revelada pelos picos nos valores do potássio apresentados pelos registros do espectrômetro em diversas linhas de vốo.

Noutro exemplo, na área mineralizada a chumbo e zinco, próxima às minas de cobre, observa-se em imagem de radar (Projeto Radam) alinhamento no terreno coincidente com o trend nordeste dos picos dos valores de potássio, o qual une os centros geométricos de todos os quatro afloramentos mineralizados conhecidos. A conclusão sobre o conduto dos fluidos mineralizadores é idêntica ao caso anterior. A Fig. 4 localiza os principais fatos dos dois exemplos acima.

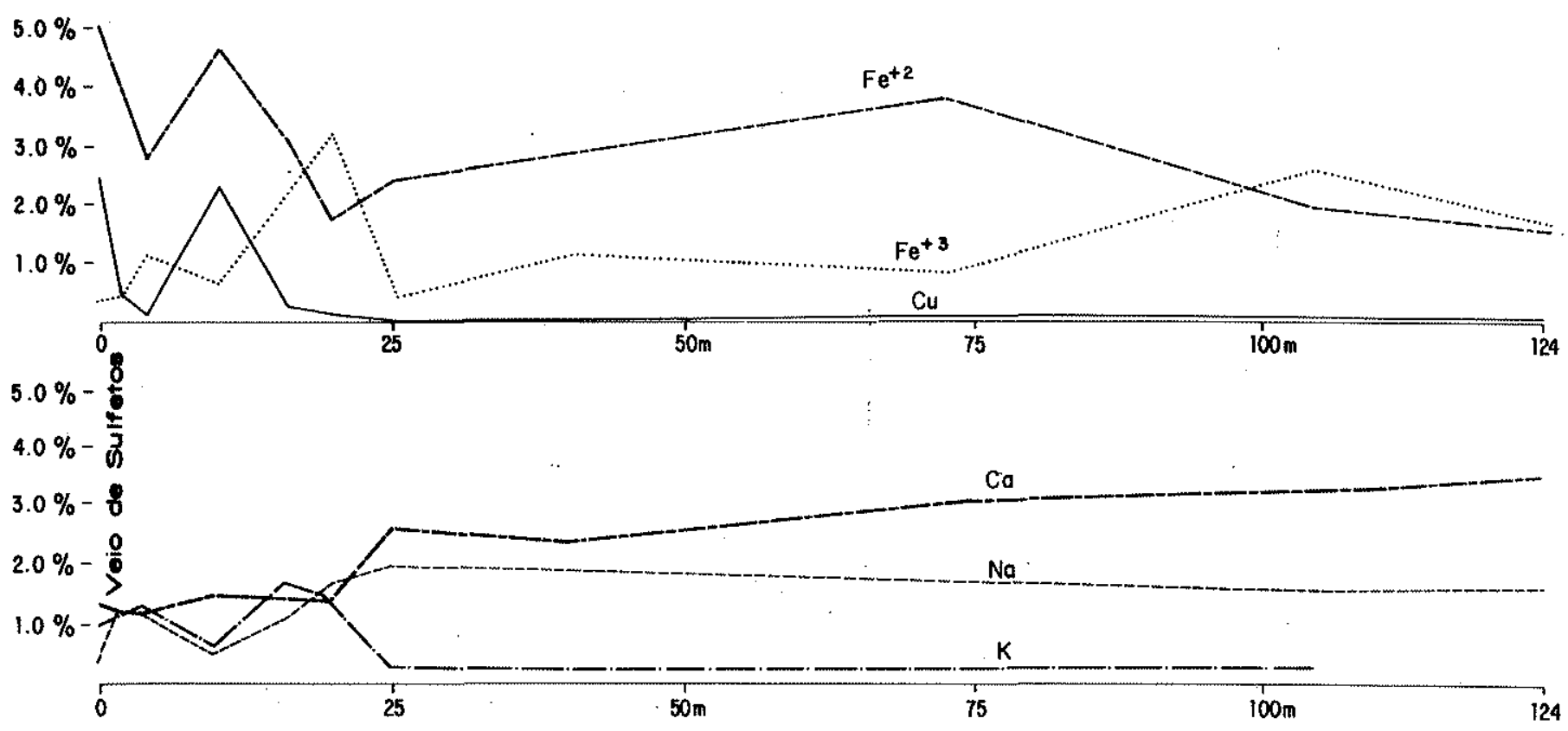

Figura 5 - Halos de alteração no nivel 500, Mina Săo Luís 
RESULTADOS A ESPERAR DA ESPECTROMETRIA No Rio Grande do Sul, o método da espectrometria aérea de raios gama forneceu resultados que permitirão concentrar recursos de prospecção em novos alvos geograficamente bem definidos e com grande potencialidade de mineralização a sulfetos. Nas áreas de ocorrências já conhecidas e estudadas, podem ser compreendidos o controle estrutural e a extensão do halo de alteração hidrotermal associado e talvez formulada hipótese genética mais detalhada e ainda assim próxima dos fatos físicos, cuja consequêencia final poderá ser a descoberta de jazida mineral em área já extensivamente pesquisada por trabalhos de superficie.

CONCLUSÕES A espectrometria de raios gama para potássio é capaz de detectar os halos de alteração da rocha associados a depósitos de origem hidrotermal. A forma geométrica da zona alterada está diretamente relacionada com o percurso das soluçðes mineralizadoras.

\section{BIBLIOGRAFIA}

BETTENCOURT, J.S. - 1972 - A Mina de Cobre de Camaquá, Rio Grande do Sul. Tese de Doutorado, IGUSP.

JACKSON, V.N., RAMOS, V.A., TERRY, S.A. e ZUZEK, A.B. - 1973 Projeto Aerogeofisico Camaquá. Executado pela Texas Instruments Inc., para a CPRM, sob convenios DNPM/CPRM e CNEN/CPRM.

DAVIS, J.D. c GUILBERT, J.M. - 1973 - Distribution of the Radioelements Potassium, Uranium, and Thorium in Selected Porphyry Copper Deposits. Bcon. Geol. 68, pp. 145-160.

LOWELL, J.D. e GUILBERT, J.M. - 1970 - Lateral and Vertical Alteration Mineralization Zoning in Porphyry. Ore Deposits. Econ. Geol. 65, pp. 373408.
MOXHAM, R.M., FOOTE, R.S. e BUNKER, C.M. - 1965 - Gamma-Ray Spectrometer Studies of Hydrothermally Altered Rocks, Econ. Geol. 60, pp. 653-671.

ROSE, A.W. - 1970 - Zonal Relations of Walirock Alteration and Sulfide Distribution at Porphyry Copper Deposits. Econ. Geol. 65, pp. 920-936.

SMIRNOV, V.I. - 1976 - Geology of Mineral Deposits. MIR Publishers, Moscou, pp. 211-344.

VILLWOCK, J.A. - 1979 - Relatório de Análises Petrográficas e Calcográficas. Arquivos da Companhia Brasileira do Cobre.

Recebido em 19 de outubro de 1979. 